\title{
A neurocomputational investigation of reinforcement-based decision making as a candidate latent vulnerability mechanism in maltreated children
}

\author{
MATTIA I. GERIN,${ }^{a, b}$ VANESSA B. PUETZ,${ }^{a, b}$ R. JAMES R. BLAIR, ${ }^{c}$ STUART WHITE, ${ }^{c}$ ARJUN SETHI ${ }^{a}$ \\ FERDINAND HOFFMANN,,$^{a, b}$ AMY L. PALMER, ${ }^{a}$ ESSI VIDING, ${ }^{a}$ AND EAMON J. MCCRORY ${ }^{a, b}$ \\ ${ }^{a}$ University College London; ${ }^{b}$ Anna Freud National Centre for Children and Families; and ${ }^{c}$ Boys Town National Research Hospital
}

\begin{abstract}
Alterations in reinforcement-based decision making may be associated with increased psychiatric vulnerability in children who have experienced maltreatment. A probabilistic passive avoidance task and a model-based functional magnetic resonance imaging analytic approach were implemented to assess the neurocomputational components underlying decision making: (a) reinforcement expectancies (the representation of the outcomes associated with a stimulus) and (b) prediction error signaling (the ability to detect the differences between expected and actual outcomes). There were three main findings. First, the maltreated group $(n=18$; mean age $=13)$, relative to nonmaltreated peers $(n=19$; mean age $=13)$, showed decreased activity during expected value processing in a widespread network commonly associated with reinforcement expectancies representation, including the striatum (especially the caudate), the orbitofrontal cortex, and medial temporal structures including the hippocampus and insula. Second, consistent with previously reported hyperresponsiveness to negative cues in the context of childhood abuse, the maltreated group showed increased prediction error signaling in the middle cingulate gyrus, somatosensory cortex, superior temporal gyrus, and thalamus. Third, the maltreated group showed increased activity in frontodorsal regions and in the putamen during expected value representation. These findings suggest that early adverse environments disrupt the development of decision-making processes, which in turn may compromise psychosocial functioning in ways that increase latent vulnerability to psychiatric disorder.
\end{abstract}

Childhood maltreatment encompasses various early adverse experiences, including physical and emotional neglect, emotional, physical, and sexual abuse, as well as witnessing domestic violence. Maltreatment is one of the most profound insults to normal development, and it is strongly associated with several maladaptive outcomes including poor mental and physical health as well as reduced economic productivity across the life span (Gilbert et al., 2009; Lansford et al., 2002; Widom, Czaja, Bentley, \& Johnson, 2012). It is noteworthy that individuals with a psychiatric disorder who have experienced childhood maltreatment show higher rates of comorbidity and symptom severity (Cougle, Timpano, Sachs-Ericsson, Keough, \& Riccardi, 2010; Teicher \& Samson, 2013) and are less likely to respond to treatment (Nanni, Uher, \& Danese, 2012). Furthermore, epidemiological data have estimated that childhood abuse and neglect account for up to $45 \%$ of the risk of childhood-onset psychiatric disorders and for approximately $30 \%$ of adult and adolescentonset disorders (Green et al., 2010). In line with these find-

This work was funded by UK Economic and Social Research Council Grant ES/K005723/1 (to E.J.M. [Principal Investigator] and E.V.) and a PhD Impact studentship (M.I.G.) jointly funded by University College London and the Anna Freud National Centre for Children and Families. The last two authors contributed equally to this work.

Address correspondence and reprint requests to: Mattia Indi Gerin, Division of Psychology and Language Sciences, University College London, Gower Street, London WC16BT, UK; E-mail: mattia.gerin.13@ucl.ac.uk. ings, population-attributable risk assessments from large cross-cultural data sets have indicated that eradicating childhood abuse and neglect could reduce the occurrence of childhood-onset psychopathology by more than 50\% (Kessler et al., 2010).

\section{The Theory of Latent Vulnerability}

Despite the abundance of evidence linking early adversity with negative outcome, there is a relative paucity of knowledge regarding the mechanisms through which increased psychiatric vulnerability becomes instantiated. The theory of latent vulnerability (McCrory \& Viding, 2015; McCrory, Gerin, \& Viding, 2017) offers a systems-level approach that places emphasis on the neurocognitive mechanisms that link early adversity to future psychopathology. According to this account, childhood maltreatment leads to alterations in several neurobiological and cognitive systems, which are understood as developmental recalibrations to abusive and neglectful environments. Such changes are "latent" insofar as they do not inevitably result in a manifest psychological disorder and can even confer short-term functional advantages within early adverse environments. Yet, in the longterm, they come at a cost as they heighten psychiatric risk.

The majority of neuroimaging studies of childhood abuse and neglect have focused on (a) perceptual/attentional pro- 
cesses, such as threat detection (e.g., Dannlowski et al., 2012, 2013, McCrory et al., 2011, 2013; Tottenham et al., 2011); (b) low-level executive functions, especially response inhibition (Elton et al., 2014; Lim et al., 2015; Mueller et al., 2010); and, more recently, (c) affect regulation (McLaughlin, Peverill, Gold, Alves, \& Sheridan, 2015; Puetz et al., 2014, 2016) and (d) reward processing (Dennison et al., 2016; Goff et al., 2013; Hanson, Hariri, \& Williamson, 2015; Mehta et al., 2010). A number of consistent findings have emerged from these studies (see McCrory et al., 2017, for a recent review). First, in relation to threat processing, several studies have reported increased neural response (particularly in the amygdala) to threat-related cues, such as angry faces. Second, studies of explicit affect regulation and executive control have reported a pattern of increased activation in medial frontal regions, including the superior frontal gyrus and cingulate cortex in individuals who have experienced maltreatment. By contrast, during more implicit regulatory processes, maltreatment experience has typically been associated with a pattern of reduced activation in a widespread frontolimbic network. Third, studies of reward processing have generally reported reduced activation in subcortical reward-related areas, in particular the striatum. These alterations in neural function are consistent with those reported in studies of individuals presenting with common psychiatric disorders (such as anxiety and depression) and may therefore represent markers of latent vulnerability to future psychopathology (McCrory et al., 2017; McCrory \& Viding, 2015).

However, in addition to these domains of functioning, it is possible that the neurocognitive processes implicated in how an individual learns from his or her experience, may also be compromised in children exposed to maltreatment given their frequent exposure to chaotic and unpredictable environments (Cyr et al., 2010; Solomon \& George, 1999). In recent years a series of studies have documented how altered reinforcementbased decision making is implicated in a number of disorders associated with maltreatment, such as anxiety and depression (Eshel \& Roiser, 2010; Hartley \& Phelps, 2012). This suggests that altered reinforcement-based decision making may index latent vulnerability to psychiatric disorder following childhood maltreatment experience.

\section{Reinforcement-Based Decision Making and Maltreatment}

Evidence from neurodevelopmental sciences, psycholinguistics and even cognitive developmental robotics, suggest that our ability to detect patterns in the environment (i.e., contingency detection) is crucial for the acquisition of a number of skills, ranging from basic perpetual abilities to higher order cognitive functions, including language, affect regulation, and relevant to this study, reinforcement-based decision making (Ellis, 2006; Nagai, Asada, \& Hosoda, 2006; Reeb-Sutherland, Levitt, \& Fox, 2012). Despite preliminary findings linking maltreatment to neural changes in the context of reward processing (Dillon et al., 2009; Hanson et al., 2015) and outcome monitoring (Lim et al., 2015), no prior study has investigated alterations in the neural systems mediating reinforcement-based decision making and its computational components in maltreated individuals.

During normal development, our innate ability for contingency detection is fostered through sensitive caretaking. However, maltreatment experiences disrupt the species normative learning environment as the child is exposed to extreme and erratic parental affective reactions and/or a paucity or inconsistency in the availability of primary reinforcers. In the case of physical maltreatment, punishments are unpredictable and extreme, compromising contingency learning by biasing attention toward negative cues (e.g., McCrory et al., 2011; Shackman, Shackman, \& Pollak, 2007). This in turn may limit the resources available (allostatic load) for the development of a range of normative cognitive functions (Rogosch, Dackis, \& Cicchetti, 2011), and reduce the opportunities necessary for learning by inducing a more avoidant exploratory style (Cicchetti \& Doyle, 2016; Cicchetti, Rogosch, \& Toth, 2006; Cyr et al., 2010). In the case of physical and emotional neglect, which represent common forms of maltreatment, basic reinforcers, such as food and emotional warmth, are not only less frequent but also less predictable (Gilbert et al., 2009; Radford, Corral, Bradley, \& Fisher, 2011). These conditions are likely to contribute to the formation of abnormal expectancies representation of stimulusoutcome (S-O) and responses-outcome (R-O) associations. In other words, it is possible that maltreatment experience leads to alterations in the neurocomputational processes critical for reinforcement-based decision making.

\section{Neurocomputational Processes of Reinforcement- Based Decision Making}

Behavioral and computational neuroimaging research suggests that at least two processes underlie successful reinforcement-based decision making: (a) expected value (EV) representation (i.e., the reinforcement expectancies associated with a stimulus or action) and (b) prediction error (PE; i.e., the ability to detect the difference between the actual from the expected outcome associated with a stimulus or action; Clithero \& Rangel, 2013; O’Doherty, Hampton, \& Kim, 2007; Rescorla \& Wagner, 1972).

These two components are highly interdependent: PE signals are thought to alter the EV associated with a stimulus or action while EV representation is directly related to the strength of the PE response to a given outcome. Evidence from computational model-based studies and animal models have shown that these two processes engage overlapping frontostriatal circuitry with its central nodes in the dorsal striatum (DS) and ventral striatum (VS) and the orbitofrontal cortex (OFC; Clithero \& Rangel, 2013; O’Doherty, 2011; O'Doherty et al., 2004; Tanaka et al., 2016; Valentin \& O'Doherty, 2009). Other brain areas implicated in PE and EV signaling include the globus pallidus, thalamus, and medial and lateral temporal regions, such as the hippocampus, 
insula, and superior temporal gyrus (Amiez et al., 2013; Bach et al., 2014; Glimcher, 2011; Zénon et al., 2016). Nodes associated with the salience network have consistently been implicated during PE signaling, including the amygdala, insula, and dorsal portions of the cingulate gyrus (Amiez et al., 2013; Garrison, Erdeniz, \& Done, 2013; Kosson et al., 2006).

\section{Reinforcement-Based Decision Making and Psychiatric Disorder}

Extant neuroimaging and behavioral data suggest that alterations in the mechanisms underlying reinforcement-based learning and decision making may contribute to the emergence and the maintenance of psychiatric conditions commonly associated with childhood maltreatment, such as anxiety, depression, conduct problems, and substance abuse (Eshel \& Roiser, 2010; Grant, Contoreggi, \& London, 2000; Hartley \& Phelps, 2012; Matthys, Vanderschuren, \& Schutter, 2012; Schoenbaum, Roesch, \& Stalnaker, 2006). Neuroimaging studies of these disorders have typically reported a pattern of decreased neural activation during reinforcement expectancies representation and outcome anticipation in the orbitostriatal circuitry (Benson, Guyer, Nelson, Pine, \& Ernst, 2014; Finger et al., 2011; Forbes et al., 2006, 2009; Galván \& Peris, 2014; May, Stewart, Migliorini, Tapert, \& Paulus, 2013; Schoenbaum et al., 2006; Smoski et al., 2009; Smoski, Rittenberg, \& Dichter, 2011; Stringaris et al., 2015). Reduced neural response in the striatum (especially the caudate), OFC, and the insula have also been reported in recent computational functional magnetic resonance imaging (fMRI) studies of EV and PE representation in anxiety, conduct disorder, and addiction (White et al., 2013, 2014, 2017; White, Tyler, Botkin, et al., 2016; White, Tyler, Erway, et al., 2016). This is in line with animal models of early adversity (e.g., Pani, Porcella, \& Gessa, 2000) and with neuroimaging data of reward processing with institutionalized individuals (Mehta et al., 2010).

\section{Hypotheses}

In the current study, we examined reinforcement-based decision making, and its neurocomputational correlates, as a potential candidate system for indexing latent vulnerability among maltreated individuals. In order to investigate maltreatment-related changes in EV and PE neural signaling, children (10-15 years) with and without documented abuse and neglect were presented in the scanner with a probabilistic passive avoidance task. This task has been used previously with individuals of similar age ranges, as well as with patients with psychiatric condition associated with maltreatment (White et al., 2013, 2017). Briefly, participants were required to learn what stimuli were associated with a higher probability of winning or losing points, and respond to (actively approach) the reward stimuli and withhold the response to (passively avoid) the punishment stimuli.
A model-based fMRI analytic method was implemented to assess the computational processes underlying EV and PE representations. Such an approach offers the opportunity to generate regressors of interest that go beyond stimulus inputs and behavioral responses. This can help uncover hidden functions and variables by showing how the brain implements a particular process (O'Doherty et al., 2007). A model-based approach allowed us to detect with greater sensitivity the neural signal underlying the computations necessary for EV and PE representation.

We hypothesized that for both approached and avoided stimuli, children with maltreatment experience would show reduced modulation of blood oxygen level dependent (BOLD) responses by $\mathrm{EV}$ in four regions of interest (ROIs): the DS and VS striatum, the medial OFC (mOFC), and the lateral OFC (IOFC). As noted earlier, this is in line with evidence from studies of reinforcement expectancies representation in those psychiatric disorders associated with maltreatment, with the animal literature of early adversity, and with some preliminary evidence from studies of extreme neglect (e.g., Forbes et al., 2009; Mehta et al., 2010; Smoski et al., 2011; Stringaris et al., 2015; White et al., 2013, 2017). In addition, consistent with substantial evidence of increased neural activation to negative stimuli and negative feedback among abused and neglected children (e.g., Lim et al., 2015; McCrory et al., 2011; McLaughlin et al., 2015), we hypothesized that children with maltreatment experience would show increased modulation of BOLD responses by PE during punishment feedback in four ROIs: the amygdala, the insula, and the anterior cingulate cortex (ACC) and midcingulate cortex (MCC).

In addition, we conducted a number of exploratory analyses related to PE modulated brain response for reward feedback. Extant data from animal models of early adversity and from studies of psychiatric conditions associated with maltreatment provide conflicting findings (Anisman \& Matheson, 2005; Dillon et al., 2009; Hanson et al., 2015). Some studies suggest no maltreatment-related nor psychiatric-related changes in consummatory behavior, positive outcomes processing, and their related neural signaling in striatal and orbitofrontal regions (Dillon et al., 2009; Mehta et al., 2010; Pryce, Dettling, Spengler, Schnell, \& Feldon, 2004; Stringaris et al., 2015; Ubl et al., 2015). In contrast, other studies report a pattern of decreased neural signaling as well as reduced behavioral response to receiving reward (Gotlib et al., 2010; Hanson et al., 2015; Kalinichev, Easterling, \& Holtzman, 2001; Matthews \& Robbins, 2003; Willner, 2005).

\section{Methods}

\section{Participants}

Forty-one children aged 10-15 years participated in this study: 20 with a documented experience of maltreatment (MT group) recruited via a Social Services Department and 21 with no prior Social Service contact recruited via 
schools/advertisements (NMT group). Exclusion criteria included the presence of a pervasive developmental disorder, neurological abnormalities, standard MRI contraindications, and an IQ below 70. Two participants from each group were excluded from the final analyses due to movement artifacts leaving a final sample of 37 children (MT group, $N=$ 18; NMT group $N=19$ ). Consent was obtained from the child's legal guardian, and assent to participate was obtained from all children. Procedures were approved by University College London Research Ethics Committee (0895/002). Participant details of the final sample are reported in Table 1.

\section{Measures}

Maltreatment history. History and severity of abuse type (neglect, emotional, sexual, and physical abuse and intimate partner violence) was provided by the child's social worker or the adoptive parent (on the basis of Social Services reports). Severity of each abuse type was rated on a scale from 0 (not present) to 4 (Table 2) in line with an established measure of maltreatment (Kaufman, Jones, Stieglitz, Vitulano, \& Mannarino, 1994). In addition, age of onset and duration of maltreatment by subtype was estimated on the basis of the file information.

Psychiatric symptomatology. The Trauma Symptom Checklist for Children (TSCC), a self-report measure of affective and trauma-related symptomatology was administered to all participants (Table 1; Briere, 1996). The Strengths and Difficulties Questionnaire (SDQ) was completed by parents or caregiver to assess general functioning (Table 1; Goodman, 1997).

Cognitive ability. Cognitive functioning was assessed using two subscales of the Wechsler Abbreviated Scales of Intelligence (Wechsler, 1997).

Table 1. Demographics and psychiatric symptomatology of MT and NMT participants included in the functional magnetic resonance analyses

\begin{tabular}{|c|c|c|c|c|c|}
\hline \multirow[b]{2}{*}{ Measures } & \multicolumn{2}{|c|}{$\operatorname{MT}(n=18)$} & \multicolumn{2}{|c|}{$\operatorname{NMT}(n=19)$} & \multirow[b]{2}{*}{$p$} \\
\hline & \multicolumn{2}{|c|}{$n$} & \multicolumn{2}{|c|}{$n$} & \\
\hline Gender (female) & \multicolumn{2}{|c|}{$10(56 \%)$} & \multicolumn{2}{|c|}{$13(68 \%)$} & .42 \\
\hline Ethnicity & \multirow{2}{*}{\multicolumn{2}{|c|}{$15(83 \%)$}} & & .37 \\
\hline White \& White mixed & & & \multicolumn{2}{|c|}{$13(68 \%)$} & \\
\hline Asian & \multicolumn{2}{|c|}{$2(11 \%)$} & \multirow{2}{*}{\multicolumn{2}{|c|}{$\begin{array}{l}1(5 \%) \\
3(16 \%)\end{array}$}} & \\
\hline Black & \multicolumn{2}{|c|}{$1(6 \%)$} & & & \\
\hline Other & \multicolumn{2}{|c|}{$0(0 \%)$} & \multicolumn{2}{|c|}{$2(10 \%)$} & \\
\hline \multicolumn{6}{|l|}{ SES education level } \\
\hline 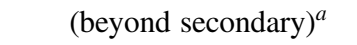 & \multicolumn{2}{|c|}{$9(50 \%)$} & \multicolumn{2}{|c|}{$13(60 \%)$} & .26 \\
\hline & Mean & $S D$ & Mean & $S D$ & $p$ \\
\hline Age (years) & 13.01 & 1.31 & 13.15 & 1.46 & .75 \\
\hline Pubertal status ${ }^{b}$ & 2.06 & 0.84 & 1.92 & 0.49 & .44 \\
\hline WASI-IQ & 108.06 & 16.41 & 108.84 & 13.57 & .87 \\
\hline \multicolumn{6}{|l|}{$\mathrm{TSCC}^{c}$} \\
\hline Anxiety & 43.28 & 7.98 & 43.47 & 8.71 & .94 \\
\hline Depression & 45.00 & 7.10 & 43.05 & 7.49 & .42 \\
\hline PTSD & 43.61 & 6.18 & 42.16 & 13.00 & .67 \\
\hline Met clinical threshold & 1 & & 0 & & \\
\hline \multicolumn{6}{|l|}{$\mathrm{SDQ}^{d} \mathrm{P}^{d}$} \\
\hline Total score & 11.50 & 8.33 & 5.42 & 4.13 & $.01 *$ \\
\hline Emotional symptoms & 2.61 & 2.30 & 1.53 & 1.71 & .11 \\
\hline Conduct problem & 2.72 & 2.72 & 0.84 & 1.17 & $.013^{*}$ \\
\hline Hyperactivity/inattention & 4.28 & 3.04 & 2.00 & 1.60 & $.009 *$ \\
\hline Peer relationship & 1.89 & 1.84 & 1.05 & 1.13 & .10 \\
\hline Prosocial behavior & 7.61 & 2.33 & 8.27 & 2.51 & .42 \\
\hline
\end{tabular}

Note: MT, maltreated group; NMT, nonmaltreated group; SES, socioeconomic status; WASI-IQ, Wechsler Abbreviated Scales of Intelligence, two IQ subscales (Wechsler, 1999); TSCC, Trauma Symptom Checklist for Children; SDQ-P, Strength and Difficulties Questionnaire-Parent report.

${ }^{a}$ Completed by caretaker.

${ }^{b}$ Composite score of self-report and parent rating of Puberty Development Scale.

${ }^{c}$ Three MT and six non-MT participants met the threshold for underresponsiveness. By excluding those individuals, the scores did not differ across the two groups.

${ }^{d}$ Missing data for $1 \mathrm{MT}$

$* p<.05$. 
Table 2. Abuse subtype frequency, severity, estimated onset age and duration (years) in the MT group

\begin{tabular}{lll}
\hline \hline \multicolumn{1}{c}{ Abuse Subtype } & Mean & $S D$ \\
\hline Physical abuse $(n=3)$ & & \\
$\quad$ Severity (0-4) & 0.33 & 0.58 \\
Mean age at onset & 1.02 & 1.78 \\
Mean duration & 6.9 & 5.12 \\
Neglect $(n=15)$ & & \\
$\quad$ Severity (0-4) & 3.40 & 1.12 \\
Mean age at onset & 1.22 & 3.57 \\
Mean duration & 5.39 & 4.52 \\
Sexual abuse $(n=1)$ & & \\
$\quad$ Severity (0-4) & 2.00 & - \\
Mean age at onset & 0.72 & - \\
Mean duration & 0.50 & - \\
Emotional abuse $(n=17)$ & & \\
$\quad$ Severity (0-4) & 2.71 & 0.77 \\
Mean age at onset & 1.51 & 2.87 \\
Mean duration & 6.01 & 4.27 \\
Domestic violence $(n=11)$ & & \\
$\quad$ Severity (0-4) & 1.64 & 1.12 \\
Mean age at onset & 2.31 & 3.29 \\
Mean duration & 4.28 & 3.24 \\
\hline \hline
\end{tabular}

Behavioral fMRI paradigm. A probabilistic passive avoidance task was administered in the scanner (Figure 1; White et al., 2013, 2017). Participants were required to learn what stimuli were associated with a higher chance of winning or losing points. The task consisted of two phases: a decision phase and a feedback phase. During the decision-phase participants could either (a) actively approach (by a button press) or (b) passively avoid (by withholding a response) one of four stimuli that were presented for $1500 \mathrm{~ms}$. Each stimulus was presented 14 times in total (creating a total of 56 trials).
The stimulus presentation was followed by a randomly jittered fixation cross (0-4000 ms). During the feedback phase one of four outcomes was presented for $1500 \mathrm{~ms}$ : "you win 50 points," "you win 10 points," "you lose 50 points," or "you lose 10 points." The feedback was probabilistic as the reward and punishment stimuli led to, respectively, gains and losses $70 \%$ of the time. Moreover, one reward stimulus was associated with a higher winning rate (i.e., a maximum gain of 185 points every 10 trials) while the other stimulus had a lower winning rate (a maximum gain of 70 points every 10 trials). Similarly, one punishment stimulus led to worst outcomes (a maximum loss of 185 points every 10 trials) compared to the other (a maximum loss of 70 points over 10 trials). The participants could only win or lose points if a stimulus was approached. Thus, avoidance responses led to no feedback presentation and a fixation cross was presented instead (also for $1500 \mathrm{~ms}$ ). The feedback phase was followed by another randomly jittered fixation cross (0-4000 ms).

The behavioral data was used to model the EV and PE for each trial for each participant based on the Rescorla-Wagner model of conditioning (O'Doherty et al., 2007; Rescorla \& Wagner, 1972). The EV for the first trial of each object was set to 0 and was then updated using the following formula:

$$
\mathrm{EV}_{(t)}=\mathrm{EV}_{(t-1)}+\left(\alpha \times \mathrm{PE}_{(t-1)}\right)
$$

In this formula the $\mathrm{EV}$ of the current trial $(t)$ equaled the $\mathrm{EV}$ of the previous trial $(t-1)$ plus the PE of the previous trial multiplied by the learning rate $(\alpha)$. The learning rate was set to 0.354 , calculated by taking the average across all individually estimated learning rates via a model-fitting simulation (see the online-only supplementary material for a description of the model-fitting procedure). The PE for the current trial equaled the feedback $(F)$ of the current trial minus the EV (a)

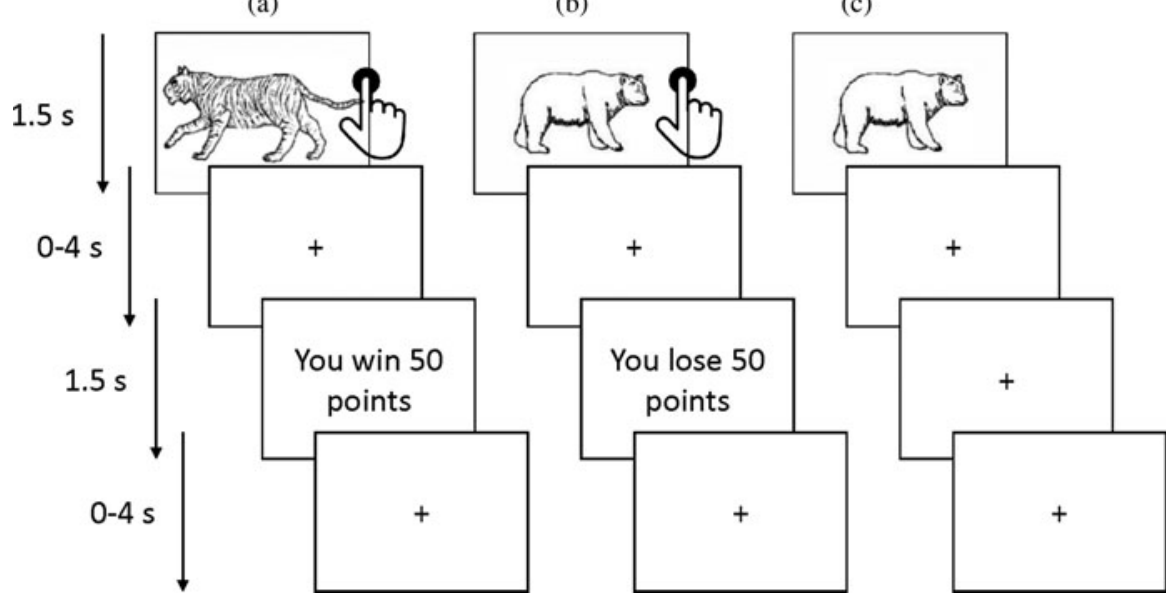

Figure 1. The probablilistic passive avoidance task. The figure illustrates the behavioral paradigm used in the scanner. Participants chose to either approach (via a button press) or avoid (by withholding a response) four stimuli presented one at a time. Reinforcement was probabilitstic such that over the course of the task two objects would result overall in gains and the other two in losses. (a) Following an approach response (i.e., a button press), a rewarding feedback is received. (b) Following an approach response, a punishing feedback is received. (c) Following an avoidance response (no button press), no feedback is received (i.e., no losses or gains). 
of the current trial: $\mathrm{PE}_{(t)}=F_{(t)}-\mathrm{EV}_{(t)}$. These parameters were then used for the model-based fMRI analyses (described below).

fMRI data acquisition. All data were acquired on a 1.5 Tesla Siemens Avanto (Siemens Medical Systems, Erlangen, Germany) MRI scanner with a 32-channel head coil during 1 run of approximately $7 \mathrm{~min}$. A total of $127 \mathrm{~T} 2$-weighted echo-planar volumes were acquired, covering the whole brain with the following acquisition parameters: slice thickness $=2$ $\mathrm{mm}$; repetition time $=85 \mathrm{~ms}$; echo time $=50 \mathrm{~ms}$; field of view $=192 \mathrm{~mm} \times 192 \mathrm{~mm}^{2} ; 35$ slices per volume, gap between slices $=1 \mathrm{~mm}$; flip angle $=90^{\circ}$ ). A high-resolution, three-dimensional T1-weighted structural scan was acquired with a magnetization prepared rapid gradient echo sequence. Imaging parameters were as follows: 176 slices; slice thickness $=1 \mathrm{~mm}$; gap between slices $=0.5 \mathrm{~mm}$; echo time $=$ $2730 \mathrm{~ms}$; repetition time $=3.57 \mathrm{~ms}$; field of view $=256 \mathrm{~m}^{2}$; matrix size $=256^{2}$; voxel size $=1 \mathrm{~mm}^{3}$.

\section{Data analysis}

Behavioral analyses. Behavioral performance on the task was assessed in relation to the number of omission errors (i.e., the number of trials in which reward stimuli were avoided) and the number of commission errors (i.e., the number of trials in which punishment stimuli were approached) as well as the total number of errors (i.e., the sum of omission and commission errors). In addition, to test the validity of the behavioral model, we examined whether the EV estimates for each trial predicted behavior (i.e., approach and avoidance responses).

fMRI analyses. Data analyses were conducted using the software package SPM8 (http://www.fil.ion.ucl.ac.uk/spm/software/spm8) implemented in Matlab 2015a (MathWorks Inc.).

Image preprocessing. After discarding the first three volumes of each run to allow for T1 equilibration effects, each participant's scans were realigned to the first image. Four participants (two in each group) were excluded from the final analyses due to more than $10 \%$ of the images being corrupted by head motion greater than $1.5 \mathrm{~mm}$. This left a final sample of $19 \mathrm{NMT}$ and $18 \mathrm{MT}(N=37)$. Data were normalized into MNI space using deformation fields from T1 scan segmentation at a voxel size of $3 \mathrm{~mm}^{3}$. The resulting images were smoothed with a 6-mm Gaussian filter and high-pass filtered at $128 \mathrm{~Hz}$.

First-level analysis. Fixed-effects statics for each individual were calculated by convolving the canonical hemodynamic response function with the box-car functions modeling the four conditions: stimulus approached, stimulus avoided, reward received, and punishment received. To reduce movement-related artifacts, we included the six motion parameters as regressors and an additional regressor to model images that were corrupted due to head motion $>1.5 \mathrm{~mm}$ and were replaced by interpolations of adjacent images $(<10 \%$ of participant's data for 9 NMT and 5 MT; no difference between groups, $p=.22$ ). Furthermore, linear polynomial expansion was applied to the percent signal change at each voxel and time point using the EV and PE estimates as parametric modulators during, respectively, the decision phase and the feedback phase.

Second-level analysis. Group analyses were conducted using a series of independent samples $t$ tests by entering the individual statistical parametric maps containing the parameter estimates of the four conditions as fixed effects and an additional "subject factor" for random effects. For the decision phase, activation in the NMT group was compared to the activation in the MT individuals for the approached stimuli modulated by the EV estimates and the avoided stimuli modulated by the EV estimates. For the feedback phase, activation in the NMT group was compared to the activation in the MT individuals in relation to the punishment feedback modulated by the PE value, and exploratory analyses were also conducted to examine the reward feedback modulated by the PE value.

Given our a priori hypotheses, small-volume corrected ROI analyses (thresholded at $p<.05$ corrected for familywise error $[\mathrm{FWE}]$ ) were performed, on the decision phase data, on the DS, VS, mOFC, and IOFC. Masks for the mOFC and IOFC were taken from the AAL atlas (WFU PickAtlas). The VS and DS masks were created based on the findings by Martinez et al. (2003) on the functional subdivisions of the striatum. For the punishment feedback condition, small volume-corrected ROI analyses (thresholded at $p<.05$, corrected for FWE) were performed in the amygdala, insula, ACC, and MCC. Masks for these regions were also taken from the AAL atlas (WFU PickAtlas).

For completeness, whole-brain analyses were also conducted, using Monte Carlo Simulation (3D ClusterSim; Ward, 2000) correcting for multiple comparisons. Clustersize corrected results are reported (voxelwise $p<.005$, $k e=75$ ) corresponding to $p=.05$ FWE corrected.

\section{Results}

\section{Behavioral results}

Demographics and symptomatology. The MT and NMT groups did not statistically differ in age, gender, pubertal status, ethnicity, socioeconomic status, intelligence (IQ), and affective symptomatology (i.e., depression, anxiety, and posttraumatic stress disorder; Table 1). The SDQ revealed difference among the two groups in overall functioning, and in relation to the conduct and hyperactivity scales.

Behavioral performance. The MT and NMT groups did not differ significantly in task performance at the behavioral level. In particular, they did not differ in relation to number 
of total $(\mathrm{MT} M=23.22, S D=8.39$; NMT $M=23.42, S D=$ $6.89 ; t=0.08, d f=35, p=.94)$, omission (MT $M=9.89, S D$ $=4.73$; NMT $M=9.39, S D=4.65 ; t=0.33, d f=35, p=$ .75 ), and commission errors (MT $M=13.83, S D=5.65$; NMT $M=13.53, S D=5.47 ; t=-0.17, d f=35, p=.87)$.

Model validity. To test the validity of the computational model, we examined the extent to which the estimated EV predicted participant's approach and avoidance responses. Consistent with the model, there was a significant relationship between predicted and observed behavior, average correlation: $r=.23$; one sample $t$ test (null $r=0$ ), $t=4.59, d f=$ $36, p<.001$. Moreover, the model was equally predictive of behavior across groups $(t=-0.15, d f=35, p=.89)$.

\section{fMRI results}

Main effects in the nonmaltreated group. Whole-brain main effect analyses were performed within the NMT group in order to ensure that the four conditions (i.e., approach trials, avoidance trials, positive feedback, and negative feedback) elicited activation patterns that were comparable to previous studies. As expected, the approach and avoidance conditions activated a network that has been previously linked with EV representation and outcome anticipation (see online-only supplementary Table S.1). Similarly (although at a more lenient cluster threshold), the punishment and reward feedbacks elicited brain activity in areas associated with PE signaling (see online-only supplementary Table S.2).

Decision phase activation modulated by EV. In line with our hypotheses, the MT group showed reduced modulation of BOLD activity in the DS (in particular in the caudate nucleus), the mOFC, and the 1OFC as a function of EV when choosing to approach a stimulus (Table 3, Figure 2). However, contrary to our hypotheses, no statistically different activation was found in the VS (Table 3, Figure 2).

When choosing to avoid a stimulus, the MT group showed reduced modulation of BOLD activity as a function of EV in all four ROIs (Table 3, Figure 3). Unexpectedly, the MT group also showed a pattern of increased bilateral modulation as a function of EV in the putamen (DS) when choosing to avoid a stimulus (Table 3 ).

Findings from the whole-brain analyses (Table 4) were consistent with our ROI analyses, indicating a widespread pattern of reduced EV signaling (for both approach and avoidance responses) and also implicated other brain regions including the globus pallidus and temporal regions, such as the insula and the hippocampus (which have in some previous studies been implicated in the representation of reinforcement expectancies).

The whole-brain data revealed that the MT group showed a pattern of increased activation in frontodorsal regions during EV processing for both approached and avoided stimuli (Table 4). In particular, the dorsomedial and dorsolateral prefrontal cortex (dmPFC, dlPFC; e.g., Brodmann area 9) and the
$\mathrm{dACC}$ and MCC were implicated. These unexpected findings were interrogated further in post hoc analyses reported below.

Feedback-phase activation modulated by PE signaling. No group difference in BOLD activity as a function of PE was found during punishment feedback in the four ROIs (i.e., amygdala, insula, dACC, and MCC; Table 3). However, MCC activity modulated by $\mathrm{PE}$ fell just above traditional significance threshold level ( $p=.052, \mathrm{FWE})$. For completeness, whole-brain analyses were also conducted (Table 4). Increased BOLD response modulated by PE was found among MT individuals in regions associated with PE processing, such as the MCC (which approached significance in the ROI analyses), the thalamus, and the superior temporal gyrus (Table 4; Amiez et al., 2013; Garrison et al., 2013). During reward feedback, no difference was found between the two groups (Table 4).

\section{Post hoc analyses}

Three sets of post hoc analyses were conducted. First, we tested whether the pattern of altered neural activation found among maltreated individuals during EV representation (Table 3) was associated with maltreatment duration and severity. These correlational analyses indicated that within the MT group, maltreatment duration was associated with reduced BOLD activity by EV in the mOFC during approach trials $(r=-46, p=.03)$.

Second, we examined whether reduced activation in orbitostriatal regions during EV representation in the MT group (Table 3) was associated with increased psychiatric symptomatology. Previous clinical computational fMRI studies that used the same passive avoidance paradigm implemented here have found that patients with anxiety and with conduct disorder show a highly comparable neural profile to the MT group in this study during EV processing (White et al., 2013, 2017; White, Tyler, Erway, et al., 2016). These clinical studies have consistently reported a pattern of reduced activation, modulated by EV, in the DS (in particular the caudate) and in the medial and lateral orbitofrontal cortices (White et al., 2013, 2017; White, Tyler, Erway, et al., 2016). Thus, our correlation analyses focused on these two areas (i.e., OFC and DS). Measures of anxiety (using the TSCC anxiety subscale and the SDQ emotional problems subscale) and conduct problems (using the SDQ conduct disorder subscale) were correlated with the peak activation in the 1OFC, $\mathrm{mOFC}$, and DS (caudate) during EV processing within the MT group. Consistent with prior studies of EV representation with anxiety patients (White et al., 2017), reduced EV neural signaling during approach trials in the 1OFC $(r=-.60, p=$ $.004)$ and in the DS $(r=-.41, p=.04)$ was associated with self-reported (TSCC) anxiety symptoms levels within the MT group. Moreover, we found a significant correlation between parental-reported measures of emotional problems on the SDQ ( $r=-.41, p=.04)$ and 1 OFC activation during avoidance trials. 
Table 3. Regions of interest demonstrating group-level differential blood oxygen level dependent responses during the task

\begin{tabular}{|c|c|c|c|c|c|c|c|c|}
\hline Group Contrast & Brain Region & $\mathrm{R} / \mathrm{L}$ & $x$ & $y$ & $Z$ & ke & $t$ & $Z$ \\
\hline \multicolumn{9}{|c|}{ Contrasts for Approached Stimuli Modulated by Expected Value } \\
\hline \multicolumn{9}{|l|}{$\mathrm{NMT}>\mathrm{MT}$} \\
\hline & DS (caudate) & $\mathrm{R}$ & 18 & 8 & 13 & 11 & 4.07 & 4.01 \\
\hline & VS & - & - & - & - & - & - & - \\
\hline & $\mathrm{mOFC}$ & $\mathrm{L}$ & -9 & 50 & -8 & 24 & 4.19 & 4.13 \\
\hline & lOFC & $\mathrm{R}$ & 39 & 44 & -8 & 88 & 4.47 & 4.39 \\
\hline & & & 27 & 47 & -5 & & 4.05 & 3.99 \\
\hline & & & 30 & 50 & -8 & & 4.05 & 3.99 \\
\hline & & $\mathrm{L}$ & -33 & 41 & -11 & 32 & 4.15 & 4.08 \\
\hline \multicolumn{9}{|l|}{$\mathrm{MT}>\mathrm{NMT}$} \\
\hline & - & - & - & - & - & - & - & - \\
\hline \multicolumn{9}{|c|}{ Contrasts for Avoided Stimuli Modulated by Expected Value } \\
\hline \multicolumn{9}{|l|}{$\mathrm{NMT}>\mathrm{MT}$} \\
\hline & DS (caudate) & $\mathrm{R}$ & 15 & 23 & -2 & 13 & 4.45 & 4.37 \\
\hline & & $\mathrm{L}$ & -33 & -10 & -11 & 7 & 4.12 & 4.06 \\
\hline & VS & $\mathrm{R}$ & 18 & 14 & -11 & 30 & 5.45 & 5.30 \\
\hline & & & 18 & 20 & -8 & & 4.52 & 4.44 \\
\hline & & $\mathrm{L}$ & -21 & 14 & -11 & 16 & 4.36 & 4.29 \\
\hline & & & -12 & 20 & -8 & & 3.67 & 3.63 \\
\hline & $\mathrm{mOFC}$ & $\mathrm{R}$ & 6 & 59 & -11 & 134 & 5.77 & 5.60 \\
\hline & & & 6 & 41 & -11 & & 5.65 & 5.49 \\
\hline & & & 18 & 14 & -14 & & 5.28 & 5.15 \\
\hline & & & -12 & 38 & -11 & & 5.15 & 5.03 \\
\hline & & & 6 & 29 & -11 & & 4.18 & 4.11 \\
\hline & & $\mathrm{L}$ & -21 & 11 & -14 & 3 & 3.75 & 3.70 \\
\hline & $1 \mathrm{OFC}$ & $\mathrm{R}$ & 42 & 29 & -8 & 97 & 5.13 & 5.01 \\
\hline & & & 45 & 32 & -11 & & 5.00 & 4.89 \\
\hline & & & 39 & 50 & -14 & & 4.78 & 4.69 \\
\hline & & & 51 & 38 & -11 & & 4.61 & 4.52 \\
\hline & & $\mathrm{R}$ & 21 & 17 & -14 & 6 & 4.75 & 4.65 \\
\hline & & $\mathrm{L}$ & -21 & 14 & -14 & 4 & 4.66 & 4.57 \\
\hline & & $\mathrm{R}$ & 42 & 17 & -14 & 6 & 4.54 & 4.45 \\
\hline & & $\mathrm{L}$ & -39 & 47 & -14 & 27 & 4.49 & 4.40 \\
\hline & & & -33 & 47 & -11 & & 4.47 & 4.39 \\
\hline \multicolumn{9}{|l|}{$\mathrm{MT}>\mathrm{NMT}$} \\
\hline & DS (putamen) & $\mathrm{L}$ & -24 & 11 & 10 & 60 & 5.53 & 5.38 \\
\hline & & & -18 & 17 & -2 & & 4.68 & 4.59 \\
\hline & & & -27 & -7 & 13 & & 3.85 & 3.80 \\
\hline & & $\mathrm{R}$ & 24 & 11 & 10 & 9 & 3.83 & 3.77 \\
\hline & VS & - & - & - & - & - & - & - \\
\hline & mOFC & - & - & - & - & - & - & - \\
\hline & $1 \mathrm{OFC}$ & - & - & - & - & - & - & - \\
\hline
\end{tabular}

Contrasts for Punishment Feedback Modulated by Prediction Error

Note: The region of interest analyses were corrected at $p<.05$ for family-wise error and at $p<.005$ for the initial threshold. R/L, right/left; $k e$, cluster extent; NMT, nonmaltreated group; MT, maltreated group; DS, dorsal striatum; VS, ventral striatum; mOFC, medial orbitofrontal cortex; lOFC, lateral orbitofrontal cortex.

Finally, post hoc analyses were performed to interrogate the unexpected whole-brain finding of increased activity, within the MT group, in a large frontodorsal cluster during EV representation during both approach and avoidance (Table 4). One interpretation for the observed increased EV neural signaling among MT individuals in frontodorsal re- gions is that it represents an adaptive response, compensating for reduced signaling in areas traditionally associated with EV computations (such as the DS, VS, mOFC, IOFC, insula, and hippocampus). In line with this post hoc hypothesis, we found that MT individuals' total error rate was negatively correlated with frontodorsal activation modulated by EV during 

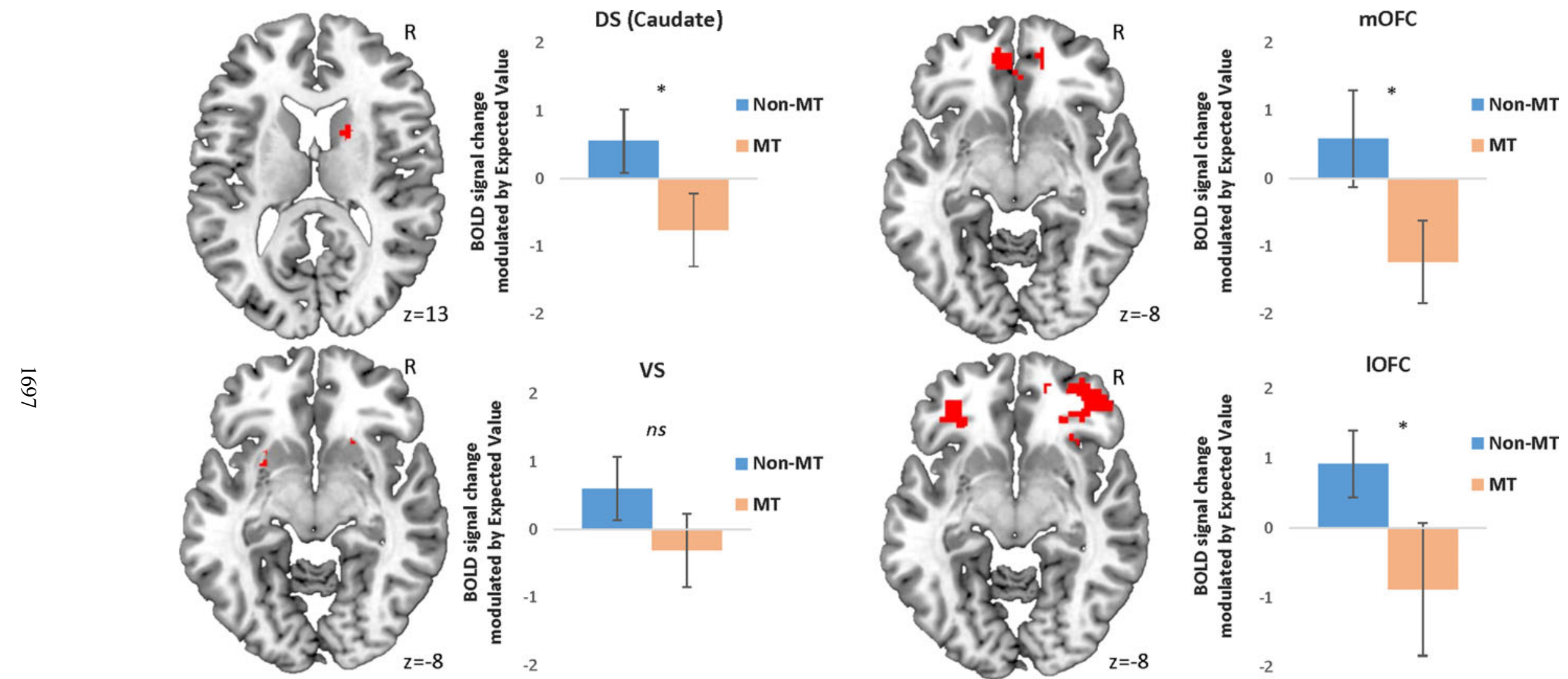

Figure 2. (Color online) Peak activation in each region of interest modulated by expected value during approach responses. Error bars represent $95 \%$ confidence intervals. * $p<.05$ corrected for family-wise error. Initial threshold $p<.05$ uncorrected. DS, dorsal striatum; mOFC, medial orbital frontal cortex; BOLD, blood oxygen level dependent; MT, maltreatment; VS, ventral striatum; 1OFC, lateral orbitofrontal cortex. 


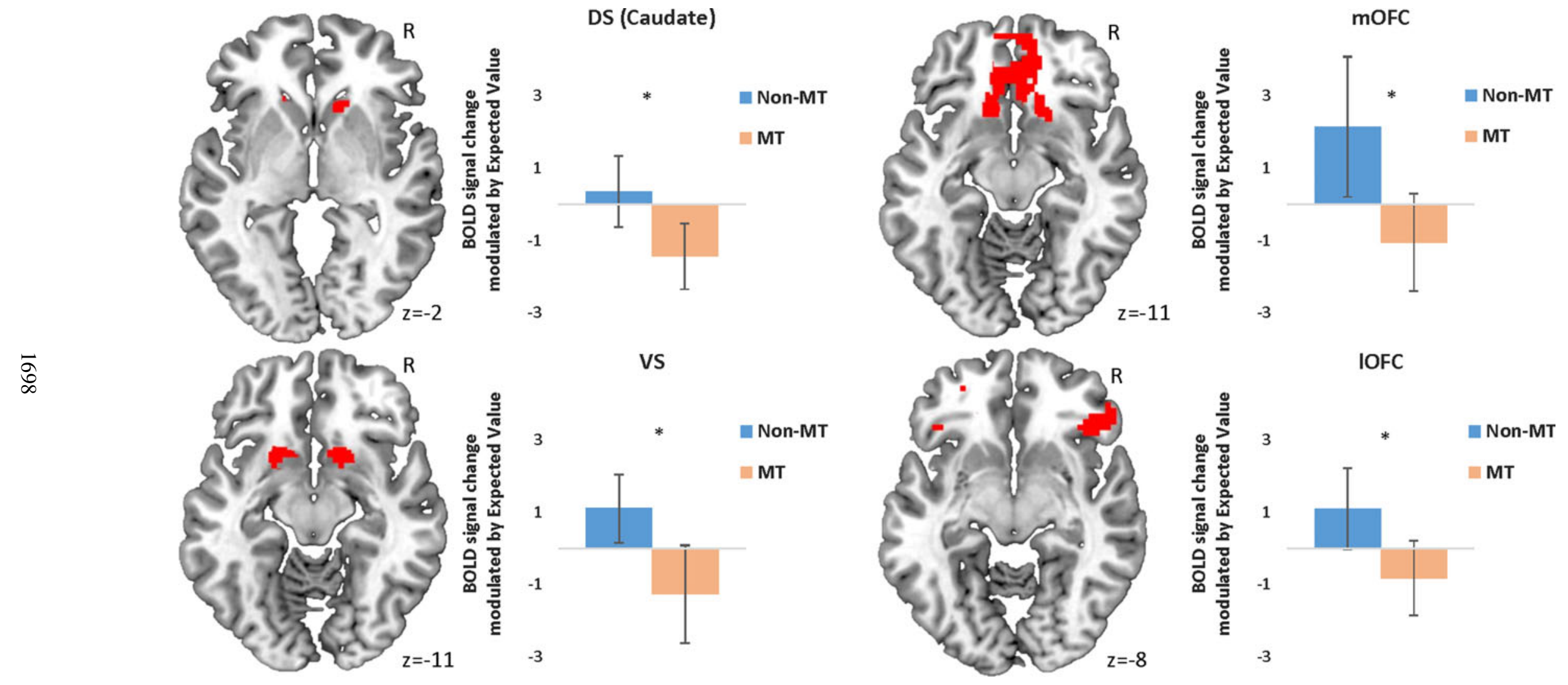

Figure 3. (Color online) Peak activation in each region of interest modulated by expected value during avoidance responses. Error bars represent $95 \%$ confidence intervals. * $p<.05$ family-wise error. Initial threshold $p<.05$ uncorrected. DS, dorsal striatum; mOFC, medial orbital frontal cortex; BOLD, blood oxygen level dependent; MT, maltreatment; VS, ventral striatum; 1OFC, lateral orbitofrontal cortex. 
Table 4. Whole brain regions demonstrating group-level differential blood oxygen level dependent responses during the task

\begin{tabular}{|c|c|c|c|c|c|c|c|c|}
\hline Group Contrast & Brain Region & $\mathrm{R} / \mathrm{L}$ & $x$ & $y$ & $z$ & ke & $t$ & $Z$ \\
\hline \multicolumn{9}{|c|}{ Contrasts for Approached Stimuli Modulated by Expected Value } \\
\hline \multicolumn{9}{|l|}{$\mathrm{NMT}>\mathrm{MT}$} \\
\hline & \multirow[t]{3}{*}{$\begin{array}{l}\text { Subthalamic nucleus ext. DS, globus pallidus, lOFC, } \\
\text { insula, thalamus/brainstem, hippocampus }\end{array}$} & \multirow[t]{3}{*}{$\mathrm{L}$} & -12 & -16 & -8 & \multirow[t]{3}{*}{244} & 4.91 & 4.81 \\
\hline & & & -24 & -4 & 13 & & 4.23 & 4.16 \\
\hline & & & -33 & 41 & -11 & & 4.15 & 4.08 \\
\hline & \multirow[t]{3}{*}{ 1OFC ext. DS, globus pallidus, insula, mOFC } & \multirow[t]{3}{*}{$\mathrm{R}$} & 30 & 47 & -8 & \multirow[t]{3}{*}{524} & 4.79 & 4.69 \\
\hline & & & 24 & 23 & -5 & & 4.65 & 4.56 \\
\hline & & & 39 & 44 & -8 & & 4.47 & 4.39 \\
\hline \multicolumn{9}{|l|}{$\mathrm{MT}>\mathrm{NMT}$} \\
\hline & \multirow[t]{3}{*}{ dmPFC/BA9 ext. dlPFC/BA9 } & \multirow[t]{3}{*}{$\mathrm{R}$} & 6 & 59 & 37 & \multirow[t]{3}{*}{104} & 4.20 & 4.13 \\
\hline & & & 39 & 38 & 37 & & 3.98 & 3.92 \\
\hline & & & 33 & 50 & 34 & & 3.76 & 3.71 \\
\hline \multicolumn{9}{|c|}{ Contrasts for Avoided Stimuli Modulated by Expected Value } \\
\hline \multicolumn{9}{|l|}{$\mathrm{NMT}>\mathrm{MT}$} \\
\hline & \multirow[t]{3}{*}{ Globus pallidus ext. VS, mOFC, $1 \mathrm{OFC}$ VS, brainstem } & \multirow[t]{3}{*}{$\mathrm{R}$} & 18 & -7 & 1 & \multirow[t]{3}{*}{823} & 7.61 & 7.25 \\
\hline & & & 6 & 59 & -11 & & 5.77 & 5.60 \\
\hline & & & 6 & 41 & -11 & & 5.65 & 5.49 \\
\hline & \multirow{4}{*}{$\begin{array}{l}\text { Insula ext. PCC, MTG, STG, MTL, DS, middle } \\
\text { occipital gyrus, calcarine sulcus }\end{array}$} & \multirow{4}{*}{$\mathrm{R}$} & & & & \multirow{4}{*}{672} & & \\
\hline & & & 42 & -25 & -5 & & 6.19 & 5.99 \\
\hline & & & 15 & -37 & 19 & & 5.69 & 5.53 \\
\hline & & & 57 & -31 & -8 & & 5.52 & 5.37 \\
\hline & \multirow[t]{3}{*}{ PCC } & \multirow[t]{3}{*}{$\mathrm{L}$} & -27 & -52 & 31 & \multirow[t]{3}{*}{85} & 5.27 & 5.15 \\
\hline & & & -15 & -40 & 16 & & 4.34 & 4.27 \\
\hline & & & -6 & -34 & 25 & & 4.02 & 3.96 \\
\hline & \multirow[t]{2}{*}{ MTL ext. hippocampus } & \multirow[t]{2}{*}{$\mathrm{L}$} & -39 & -10 & -17 & \multirow[t]{2}{*}{82} & 4.89 & 4.78 \\
\hline & & & -54 & -10 & -17 & & 3.65 & 3.61 \\
\hline $\mathrm{MT}>\mathrm{NMT}$ & & & & & & & & \\
\hline & $\begin{array}{l}\text { dACC/MCC ext. dlPFC/BA9, dmPFC/BA9, precentreal } \\
\text { gyrus, postcentral gyrus, dACC, DS (putamen) }\end{array}$ & $\mathrm{L}$ & -9 & 8 & 31 & 7342 & 8.93 & inf \\
\hline & & & -27 & -1 & 28 & & 7.34 & 7.02 \\
\hline & & & -30 & 35 & 31 & & 7.28 & 6.96 \\
\hline & Precuneus ext. PCC & $\mathrm{L}$ & -12 & -61 & 19 & 89 & 5.27 & 5.14 \\
\hline & & & -15 & -58 & 28 & & 3.85 & 3.79 \\
\hline & & & -9 & -43 & 13 & & 3.51 & 3.47 \\
\hline & Precuneus ext. PCC & $\mathrm{R}$ & 9 & -58 & 19 & 100 & 4.98 & 4.87 \\
\hline & & & 12 & -46 & 19 & & 4.44 & 4.36 \\
\hline & & & 21 & -55 & 19 & & 3.41 & 3.37 \\
\hline
\end{tabular}

Contrasts for Reward Feedback Modulated by Prediction Error

Contrasts for Punishment Feedback Modulated by Prediction Error

\begin{tabular}{|c|c|c|c|c|c|c|c|c|}
\hline \multicolumn{9}{|l|}{$\mathrm{NMT}>\mathrm{MT}$} \\
\hline & - & - & - & - & - & - & - & - \\
\hline \multicolumn{9}{|l|}{$\mathrm{MT}>\mathrm{NMT}$} \\
\hline & \multirow[t]{3}{*}{ STG ext. supramarginal gyrus } & \multirow[t]{3}{*}{$\mathrm{L}$} & -60 & -40 & 13 & \multirow[t]{3}{*}{94} & 4.21 & 4.14 \\
\hline & & & -45 & -43 & 16 & & 3.58 & 3.53 \\
\hline & & & -54 & -49 & 16 & & 3.56 & 3.51 \\
\hline & \multirow[t]{3}{*}{ MCC ext. postcentral sulcus, postcentral gyrus } & \multirow[t]{3}{*}{$\mathrm{L}$} & -18 & -34 & 37 & \multirow[t]{3}{*}{86} & 3.73 & 3.68 \\
\hline & & & -30 & -40 & 37 & & 3.54 & 3.50 \\
\hline & & & -12 & -22 & 37 & & 3.31 & 3.28 \\
\hline & \multirow[t]{3}{*}{ Thalamus ext. BA13 } & \multirow[t]{3}{*}{$\mathrm{R}$} & 9 & -10 & 19 & \multirow[t]{3}{*}{82} & 3.71 & 3.67 \\
\hline & & & 15 & -25 & 19 & & 3.68 & 3.63 \\
\hline & & & 27 & -25 & 10 & & 3.45 & 3.41 \\
\hline
\end{tabular}

Note: Whole brain analyses corrected/thresholded at $k e=75, p<.005$ (equivalent to $p<.05$ family-wise error). R/L, right/left; $k e$, cluster extent; NMT, nonmaltreated group; MT, maltreated group; DS, dorsal striatum; VS, ventral striatum; mOFC, medial orbitofrontal cortex; 1OFC, lateral orbitofrontal cortex; dlPFC, dorsolateral prefrontal cortex; BA9, Brodmann area 9; MTG, middle temporal gyrus; STG, superior temporal gyrus; MTL, medial temporal lobe; dACC, dorsal anterior cingulate cortex; MCC, middle cingulate cortex; PCC, posterior cingulate cortex. 
both approach $(r=-.45, p=.03)$ and avoidance $(r=-.41$, $p<.05)$ trials. This suggests that the degree of engagement of this frontodorsal network during EV processing contributes to improved behavioral performance on the task. To explore this effect further, the total error rate was then divided into omission and commission error rates. It was found that while the BOLD response by EV in this frontodorsal cluster during both approach and avoidance trials was significantly correlated with omission errors $(r=-.64, p=.002$ and $r=-.43, p=.04$, respectively), that was not the case for the commission errors $(r=-.15, p=.28$ and $r=-.26$, $p=.15$, respectively).

\section{Discussion}

To our knowledge, this is the first study to investigate the extent to which children with documented experiences of childhood maltreatment show alterations in the neural systems engaged with specific computations of reinforcement-based decision making. We employed a probabilistic passive avoidance task, in combination with a model-based fMRI analytic approach, in order to assess neural responses associated with EV representation and PE processing for reward and punishment cues. At the behavioral level, the children who had experienced maltreatment (MT group) did not differ from a group of nonmaltreated (NMT) peers. By contrast, at the neural level, the MT group differed from their peers in three main ways. First, the MT group demonstrated a pattern of reduced activity modulated by EV in a network commonly associated with reinforcement expectancies representation, including the orbitostriatal circuitry. Second, during losses, the MT compared to the NMT group showed increased PE signaling in frontal and temporal regions, including the mid-cingulate gyrus and the superior temporal gyrus. Third, the MT group showed increased activity in the putamen and in frontodorsal regions during EV representation.

\section{EV modulated neural response}

Reduced EV modulated neural response in corticolimbic circuitry. As predicted, maltreatment experience was associated with reduced BOLD response by $\mathrm{EV}$ in both approach and avoidance trials in the mOFC and the 1OFC, and in the DS, especially in the caudate nucleus. Reduced response in the VS was also observed, but only in the avoidance trials. Our whole-brain analyses were consistent with these findings, and also implicated the globus pallidus, the subthalamic nucleus, insula, and the hippocampus. These regions have been previously shown to be involved in reinforcement expectancy representation in typical individuals (e.g., Bach et al., 2014; Glimcher, 2011; Kosson et al., 2006; Zénon et al., 2016); reduced neural response in these same regions has been reported in studies of psychiatric disorders associated with maltreatment experience, including anxiety, conduct disorder, and depression (Gotlib et al., 2010; Ubl et al., 2015; White et al., 2013, 2017). This pattern of reduced neural response is thought to reflect impairments in the precision of EV representation (White et al., 2013, 2017). As such, the findings of the current study may reflect alterations in reinforcement-based decision making that may in turn confer increased latent vulnerability to psychiatric disorder. Our post hoc analyses, demonstrating that reduced activation in the caudate and the OFC was related to higher levels of anxiety symptomatology in the MT group, are consistent with this hypothesis. It is also noteworthy that post hoc analyses indicated a dose-dependent negative association between maltreatment duration and degree of activation in these areas, suggesting that greater maltreatment exposure was associated with more marked neurocognitive alterations.

Increased EV modulated neural response in the putamen. During EV processing for avoided stimuli, the MT group showed an unexpected pattern of increased activation relative to the NMT group in the putamen. This may initially appear surprising, given that the MT group also showed a pattern of reduced EV-related signaling in the caudate. However, studies of disorders associated with early adversity, such as depression (see Zhang, Chang, Guo, Zhang, \& Wang, 2013, for a meta-analysis) and anxiety (e.g., White et al., 2017), suggest that the caudate (but not the putamen) is less active during outcome anticipation. Moreover, data from a recent study investigating affect processing and regulation reported that children who have experienced maltreatment also show greater engagement of the putamen (but not the caudate) to negative cues (McLaughlin et al., 2015).

The putamen and the caudate are connected to different brain regions and are understood to perform different functions (Cohen \& Frank, 2009; Grahn, Parkinson, \& Owen, 2008). The caudate is thought to be crucial for EV representation, including $\mathrm{R}-\mathrm{O}$ and $\mathrm{S}-\mathrm{O}$ associations, flexible cognition, and it underpins goal-directed behavior (Grahn, Parkinson, \& Owen, 2009). By contrast, outcome expectancy is not evaluated in the putamen. Rather, this region has been implicated in less complex and less flexible types of behavioral and cognitive representations, such as habit learning (Devan, Hong, \& McDonald, 2011; Grahn et al., 2008). It has been suggested that the putamen may be recruited during the initial phases of reinforcement-based learning, with the caudate becoming more dominant during later stages of instrumental learning (Brovelli, Nazarian, Meunier, \& Boussaoud, 2011).

One possible explanation for the pattern of findings in the DS is that children with experience of maltreatment sustain activation of the putamen throughout the task, unlike their peers who progress to more flexible and complex reinforcement-based representations (indexed by their greater activation of the caudate and other regions involved in higher order $\mathrm{EV}$ processing). For maltreated individuals, it may be paramount and more adaptive to learn rapidly (at the expense of more flexible and complex EV processing) which elements in the environment are associated with punishment and should be avoided. The development of more flexible and higher order cognition in relation to reinforcement and con- 
tingency learning to negative cues may be less optimal (or even counterproductive) in environments where behavioral responses must be quickly learned to avoid punishment. Future studies are required to investigate this hypothesis by parsing out early from later stages of reinforcement-based learning differences in MT and NMT individuals.

Increased EV modulated neural response in the dorsomedial and dorsolateral frontal cortex. Our whole-brain analyses revealed a pattern of increased activation in an extended dorsofrontal network that includes the dmPFC and dlPFC prefrontal cortex (especially Brodmann Area 9), the dorsal anterior cingulate cortex (dACC) and also the MCC, which was unexpected, but which is in line with studies investigating outcome anticipation among depressed children and adolescents (Forbes et al., 2006, 2009). Recent neuroimaging studies of maltreatment have found that despite no differences in task performance, MT children show increased activation in dorsomedial and dorsolateral prefrontal regions while performing different cognitive functions (e.g., explicit affect regulation; McLaughlin et al., 2015) and response inhibition (Lim et al., 2015). It has been proposed that greater engagement of these regions involved in effortful control may represent a compensatory mechanism as more effort may be required for comparable task performance by children who have experienced maltreatment (McLaughlin et al., 2015).

In the context of this study, the engagement of this dorsofrontal network may similarly represent an adaptive response, compensating for the reduced signaling in brain areas traditionally associated with EV representation (such as the DS, VS, mOFC, IOFC, insula, and hippocampus). In line with this potential explanation, our post hoc correlational analyses indicated that, among maltreated individuals, EV modulated activation in this dorsofrontal network was associated with improved task performance, and in particular with improvement in omission (but not commission) error rate. On this basis, we speculate that a tendency for an avoidant response in the MT group (as indexed by increased neural response to punishment) is attenuated by the increased activity found in the frontodorsal region during $\mathrm{EV}$ processing. If this is the case, it suggests that the comparable behavioral performance of the groups may be driven by differential neurocomputational processes.

\section{PE-modulated neural response}

$P E$ for reward feedback. No group difference was found during PE-modulated brain activation to reward. This is in line with a large set of studies that suggests that consummatory (unlike anticipatory) neurocognitive and behavioral processes are not implicated in disorders such as depression (Stringaris et al., 2015; Ubl et al., 2015), nor appear associated with early adverse experiences (Dillon et al., 2009; Mehta et al., 2010; Pryce et al., 2004).

PE for punishment feedback. As noted earlier, extant studies on threat-detection and salience processing among maltreated children and adults have found a consistent pattern of increased activation in several regions implicated in the detection of negative cues (e.g., Dannlowski et al., 2012; McCrory et al., 2011). On this basis, we also expected an increased pattern of PE signaling during punishment feedback in the MT group in four regions: the amygdala, insula, ACC, and MCC. However, no group differences were found in these ROIs. In contrast, the whole-brain data revealed a widespread pattern of increased activation in frontal, temporal, and subcortical areas, including the MCC, the superior temporal gyrus, the postcentral gyrus, and the thalamus. This network has been extensively implicated in PE error signaling in normative samples (Amiez et al., 2013; Garrison et al., 2013). In addition, these findings are in line with the data from the only study that has investigated (noncomputationally) PE in maltreated children (Lim et al., 2015). Maltreatment-related alterations in $\mathrm{PE}$ processing for negative information may therefore be system specific insofar as they do not overlap with the brain network that is devoted to salience detection and threat processing (e.g., insula and amygdala). Future studies should test this hypothesis by directly comparing $\mathrm{PE}$ and threat-detection signaling in MT and NMT individuals.

\section{Childhood maltreatment, decision making, and latent vulnerability}

As discussed above, sensitive caregiving and appropriate parental scaffolding plays an important role in the normative development of contingency detection, which is a sine qua non for the acquisition of a number of skills and higher order cognitive functions, including reinforcement-based decision making (Ellis, 2006; Nagai et al., 2006; Reeb-Sutherland et al., 2012). However, this developmental learning process may be compromised by an impoverished and chaotic learning environment and by several other aspects associated with the maltreatment experience, such as unpredictable and severe forms of punishment.

It has been shown that an abusive environment can lead to the preferential diversion of attentional resources toward threat-related cues in the environment (McCrory et al., 2011; Pollak \& Tolley-Schell, 2003; Pollak, Vardi, Putzer Bechner, \& Curtin, 2005). Early adverse experiences may also contribute to the misattribution of negative valence to social cues in the environment that are actually neutral and nonthreatening, in line with a number of psychiatric presentations (Cooney, Atlas, Joormann, Eugène, \& Gotlib, 2006; Leppänen, Milders, Bell, Terriere, \& Hietanen, 2004). Negative attention and attribution biases may, in turn, contribute to the development of abnormal EV representation in several ways: (a) by diverting away the cognitive and attentional resources necessary for normal contingency-based learning (Rogosch et al., 2011); (b) by overweighting S-O and R-O associations in favor of negative information; or (c) by reducing the amount and quality of exploratory behavior, crucial for contingency learning and the development of normative EV 
and PE representations (Cicchetti \& Doyle, 2016; Cicchetti et al., 2006).

An alternative view is that physical and emotional neglect, common forms of childhood maltreatment (Gilbert et al., 2009; Radford et al., 2011), create aberrant environments that distort the development of flexible and contingencybased learning and context-appropriate higher order representations (e.g., Fonagy, Gergely, Jurist, \& Target, 2004; Gergely \& Watson, 1999), leading to widespread alterations in EV and PE neural signaling. It is known that these forms of neglect are characterized by environments were primary reinforcers (e.g., food) are less predictable and frequent, and where there is a lack of timely and sensitive positive affective communication and emotional reciprocity.

The ability to envisage the consequences and predict the outcomes associated with a given stimulus or action is crucial for our ability to orient, motivate, and flexibly guide behavior toward specifics goals and navigate the environment successfully (O’Doherty et al., 2004). However, abnormal EV representation can compromise this ability, leading to suboptimal decision making and maladaptive outcomes, as documented in a number of common psychiatric disorders (Eshel \& Roiser, 2010; Hartley \& Phelps, 2012; Stringaris et al., 2015; Zhang et al., 2013). Therefore, the evidence presented here suggests that abnormalities in reinforcement-based decision making may represent a promising neurocognitive candidate system to index increased psychiatric risk among individuals who have experienced early adversity.

\section{Limitations and conclusions}

The current study has a number of limitations. First, this study has a relatively small sample size and the design is cross-sectional in nature. A longitudinal design and larger sample will be necessary to investigate whether maltreatment-related alterations found in reinforcement-based decision making are associated with future psychiatric vulnerability. A second limitation pertains to the design of the passive avoidance task employed here. Although a well-validated measure of reinforcement-based decision making used in a number of prior developmental studies of psychiatric groups, this measure does not allow the parsing of EV processing from motor-output responses during the approached trials. Future neuroimaging investigations, which require the approach (or avoidance) responses to be executed after stimulus presentation, would address this issue directly. Nevertheless, the model-

\section{References}

Amiez, C., Neveu, R., Warrot, D., Petrides, M., Knoblauch, K., \& Procyk, E. (2013). The location of feedback-related activity in the midcingulate cortex is predicted by local morphology. Journal of Neuroscience, 33, 22172228. doi:10.1523/jneurosci.2779-12.2013

Anisman, H., \& Matheson, K. (2005). Stress, depression, and anhedonia: Caveats concerning animal models. Neuroscience \& Biobehavioral Reviews, 29, 525-546. doi:10.1016/j.neubiorev.2005.03.007

Bach, D. R., Guitart-Masip, M., Packard, P. A., Miró, J., Falip, M., Fuentemilla, L., \& Dolan, R. J. (2014). Human hippocampus arbitrates ap- based fMRI analytic approach implemented here allowed the estimated EVs (on a trial-by-trial and individual basis) to be convolved with the BOLD signal, facilitating the partialing out of the brain signal that was unrelated to the representation of reinforcement expectancies. Third, a recent study has shown that maltreatment exposure is more detrimental to the development of executive control functions when it occurs earlier (during infancy) than later in life (during childhood; Cowell, Cicchetti, Rogosch, \& Toth, 2015). Executive control functions, including working memory, cognitive flexibility, and inhibitory control, are central to the computations that underlie reinforcement-based learning and decision making (e.g., Ridderinkhof, van den Wildenberg, Segalowitz, \& Carter, 2004). Therefore, an examination of the timing of maltreatment exposure may contribute to a more precise understanding of the neurocomputational mechanisms through which maltreatment interferes with the development of reinforcement-based decision making. Our post hoc analyses suggest that greater duration of maltreatment relates to more considerable neurocognitive alterations; however, the heterogeneity and sample size of the recruited sample did not allow us to systematically investigate the existence of periods during which the effect of early adversity may be particularly potent (i.e., sensitive periods; Knudsen, 2004). This remains an important open question to be addressed in the future.

To conclude, this is the first study to show that childhood maltreatment may be associated with altered neurocomputational EV representation (for both punishment and reward) in a widespread corticolimbic network that includes the orbitofrontal cortex, the basal ganglia (especially the caudate), and medial temporal regions (i.e., hippocampus and insula). Moreover, in line with an account of increased neural signaling to negative stimuli and feedback in this population, an increased PE-modulated brain response during punishment trials was found in several frontal and parietal regions that have been implicated with both PE signaling and with the experiences of abuse and neglect. Consistent with the clinical literature, these neurocognitive alterations may compromise the ability of maltreated individuals to accurately predict the outcomes associated with a given stimulus or action and in turn confer increased latent vulnerability to future psychiatric disorder.

\section{Supplementary Material}

To view the supplementary material for this article, please visit https://doi.org/10.1017/S095457941700133X. proach-avoidance conflict. Current Biology, 24, 541-547. doi:10.1016/ j.cub.2014.01.046

Benson, B. E., Guyer, A. E., Nelson, E. E., Pine, D. S., \& Ernst, M. (2014) Role of contingency in striatal response to incentive in adolescents with anxiety. Cognitive, Affective, \& Behavioral Neuroscience, 15, 155-168. doi:10.3758/s13415-014-0307-6

Briere, J. (1996). Trauma Symptom Checklist for Children (TSCC): Professional manual. Odessa, FL: Psychological Assessment Resources. 
Brovelli, A., Nazarian, B., Meunier, M., \& Boussaoud, D. (2011). Differential roles of caudate nucleus and putamen during instrumental learning. NeuroImage, 57, 1580-1590. doi:10.1016/j.neuroimage.2011.05.059

Cicchetti, D., \& Doyle, C. (2016). Child maltreatment, attachment and psychopathology: Mediating relations. World Psychiatry, 15, 89-90. doi:10. 1002/wps.20337

Cicchetti, D., Rogosch, F. A., \& Toth, S. L. (2006). Fostering secure attachment in infants in maltreating families through preventive interventions. Development and Psychopathology, 18, 623-649. doi:10.1017/S09545 79406060329

Clithero, J. A., \& Rangel, A. (2013). Informatic parcellation of the network involved in the computation of subjective value. Social Cognitive and Affective Neuroscience, 9, 1289-1302. doi:10.1093/scan/nst106

Cohen, M. X., \& Frank, M. J. (2009). Neurocomputational models of basal ganglia function in learning, memory and choice. Behavioural Brain Research, 199, 141-156. doi:10.1016/j.bbr.2008.09.029

Cooney, R. E., Atlas, L. Y., Joormann, J., Eugène, F., \& Gotlib, I. H. (2006). Amygdala activation in the processing of neutral faces in social anxiety disorder: Is neutral really neutral? Psychiatry Research Neuroimaging, 148, 55-59. doi:10.1016/j.pscychresns.2006.05.003

Cougle, J. R., Timpano, K. R., Sachs-Ericsson, N., Keough, M. E., \& Riccardi, C. J. (2010). Examining the unique relationships between anxiety disorders and childhood physical and sexual abuse in the National Comorbidity Survey-Replication. Psychiatry Research, 177, 150-155. doi:10.1016/j.psychres.2009.03.008

Cowell, R. A., Cicchetti, D., Rogosch, F. A., \& Toth, S. L. (2015). Childhood maltreatment and its effect on neurocognitive functioning: Timing and chronicity matter. Development and Psychopathology, 27, 521-533. doi:10.1017/S0954579415000139

Cyr, C., Euser, E. M., Bakermans-Kranenburg, M. J., van Ijzendoorn, M. H., Ackerman, B. P., Izard, C. E., . . . Bakermans-Kranenburg, M. J. (2010). Attachment security and disorganization in maltreating and high-risk families: A series of meta-analyses. Development and Psychopathology, 22, 87. doi:10.1017/S0954579409990289

Dannlowski, U., Kugel, H., Huber, F., Stuhrmann, A., Redlich, R., Grotegerd, D., . . . Suslow, T. (2013). Childhood maltreatment is associated with an automatic negative emotion processing bias in the amygdala. $\mathrm{Hu}$ man Brain Mapping, 34, 2899-2909. doi:10.1002/hbm.22112

Dannlowski, U., Stuhrmann, A., Beutelmann, V., Zwanzger, P., Lenzen, T., Grotegerd, D., . . . Kugel, H. (2012). Limbic scars: Long-term consequences of childhood maltreatment revealed by functional and structural magnetic resonance imaging. Biological Psychiatry, 71, 286-293. doi:10.1016/j.biopsych.2011.10.021

Dennison, M. J., Sheridan, M. A., Busso, D. S., Jenness, J. L., Peverill, M., Rosen, M. L., \& McLaughlin, K. A. (2016). Neurobehavioral markers of resilience to depression amongst adolescents exposed to child abuse. Journal of Abnormal Psychology, 125, 1201-12012. doi:10.1037/ abn0000215

Devan, B. D., Hong, N. S., \& McDonald, R. J. (2011). Parallel associative processing in the dorsal striatum: Segregation of stimulus-response and cognitive control subregions. Neurobiology of Learning and Memory, 96, 95-120. doi:10.1016/j.nlm.2011.06.002

Dillon, D. G., Holmes, A. J., Birk, J. L., Brooks, N., Lyons-Ruth, K., \& Pizzagalli, D. A. (2009). Childhood adversity is associated with left basal ganglia dysfunction during reward anticipation in adulthood. Biological Psychiatry, 66, 206-213. doi:10.1016/j.biopsych.2009.02.019

Ellis, N. C. (2006). Language acquisition as rational contingency learning. Applied Linguistics, 27, 1-24. doi:10.1093/applin/ami038

Elton, A., Tripathi, S. P., Mletzko, T., Young, J., Cisler, J. M., James, G. A., \& Kilts, C. D. (2014). Childhood maltreatment is associated with a sexdependent functional reorganization of a brain inhibitory control network. Human Brain Mapping, 35, 1654-1667. doi:10.1002/hbm.22280

Eshel, N., \& Roiser, J. P. (2010). Reward and punishment processing in depression. Biological Psychiatry, 68, 118-124. doi:10.1016/j.biopsych. 2010.01.027

Finger, E. C., Marsh, A. A., Blair, K. S., Reid, M. E., Sims, C., Ng, P., . . Blair, R. J. R. (2011). Disrupted reinforcement signaling in the orbitofrontal cortex and caudate in youths with conduct disorder or oppositional defiant disorder and a high level of psychopathic traits. American Journal of Psychiatry, 168, 152-162. doi:10.1176/appi.ajp.2010.10010129

Fonagy, P., Gergely, G., Jurist, E., \& Target, M. (2004). The social biofeedback theory of parental affect-mirroring: The development of emotional self-awareness and self-control in infancy. In Affect regulation, mentalization, and the development of the self (2nd ed., pp. 145-203). London:
Karnac Books. Retrieved from http://www.pep-web.org.libproxy.ucl.ac. uk/document.php?id=ijp.077.1181a

Forbes, E. E., Christopher May, J., Siegle, G. J., Ladouceur, C. D., Ryan, N. D. Carter, C. S., . . . Dahl, R. E. (2006). Reward-related decision-making in pediatric major depressive disorder: An fMRI study. Journal of Child Psychology and Psychiatry, and Allied Disciplines, 47, 1031-1040. doi:10.1111/j.1469-7610.2006.01673.x

Forbes, E. E., Hariri, A. R., Martin, S. L., Silk, J. S., Moyles, D. L., Fisher, P. M. . . . Dahl, R. E. (2009). Altered striatal activation predicting real-world positive affect in adolescent major depressive disorder. American Journal of Psychiatry, 166, 64-73. doi:10.1176/appi.ajp.2008.07081336

Galván, A., \& Peris, T. S. (2014). Neural correlates of risky decision making in anxious youth and healthy controls. Depression and Anxiety, 31, 591598. doi:10.1002/da.22276

Garrison, J., Erdeniz, B., \& Done, J. (2013). Prediction error in reinforcement learning: A meta-analysis of neuroimaging studies. Neuroscience \& Biobehavioral Reviews, 37, 1297-1310. doi:10.1016/j.neubiorev.2013.03.023

Gergely, G., \& Watson, J. S. (1999). Early socio-emotional development: Contingency perception and the social-biofeedback model. In P. Rochat (Ed.), Early social cognition: Understanding others in the first months of life (pp. 101-136). Mahwah, NJ: Erlbaum.

Gilbert, R., Widom, C. S., Browne, K., Fergusson, D., Webb, E., \& Janson, S. (2009). Burden and consequences of child maltreatment in high-income countries. Lancet, 373, 68-81. doi:10.1016/S0140-6736(08)61706-7

Glimcher, P. W. (2011). Understanding dopamine and reinforcement learning: The dopamine reward prediction error hypothesis. Proceedings of the National Academy of Sciences, 108, 15647-15654. doi:10.1073/ pnas. 1014269108

Goff, B., Gee, D. G., Telzer, E. H., Humphreys, K. L., Gabard-Durnam, L., Flannery, J., \& Tottenham, N. (2013). Reduced nucleus accumbens reactivity and adolescent depression following early-life stress. Neuroscience, 249, 129-138. doi:10.1016/j.neuroscience.2012.12.010

Goodman, R. (1997). The Strengths and Difficulties Questionnaire: A research note. Journal of Child Psychology and Psychiatry, and Allied Disciplines, 38, 581-586. doi:10.1097/00004583-200111000-00015

Gotlib, I. H., Hamilton, J. P., Cooney, R. E., Singh, M. K., Henry, M. L., \& Joormann, J. (2010). Neural processing of reward and loss in girls at risk for major depression. Archives of General Psychiatry, 67, 380-387. doi:10.1001/archgenpsychiatry.2010.13

Grahn, J. A., Parkinson, J. A., \& Owen, A. M. (2008). The cognitive functions of the caudate nucleus. Progress in Neurobiology, 86, 141-155. doi:10.1016/j.pneurobio.2008.09.004

Grahn, J. A., Parkinson, J. A., \& Owen, A. M. (2009). The role of the basal ganglia in learning and memory: Neuropsychological studies. Behavioural Brain Research, 199, 53-60. doi:10.1016/j.bbr.2008.11.020

Grant, S., Contoreggi, C., \& London, E. D. (2000). Drug abusers show impaired performance in a laboratory test of decision making. Neuropsychologia, 38, 1180-1187. doi:10.1016/S0028-3932(99)00158-X

Green, J. G., McLaughlin, K. A., Berglund, P. A., Gruber, M. J., Sampson, N. A., Zaslavsky, A. M., \& Kessler, R. C. (2010). Childhood adversities and adult psychiatric disorders in the national comorbidity survey replication: I. Associations with first onset of DSM-IV disorders. Archives of General Psychiatry, 67, 113-123. doi:10.1001/archgenpsychiatry.2009.186

Hanson, J. L., Hariri, A. R., \& Williamson, D. E. (2015). Blunted ventral striatum development in adolescence reflects emotional neglect and predicts depressive symptoms. Biological Psychiatry, 78, 598-605. doi:10. 1016/j.biopsych.2015.05.010

Hartley, C. A., \& Phelps, E. A. (2012). Anxiety and decision-making. Biological Psychiatry, 72, 113-118. doi:10.1016/j.biopsych.2011.12.027

Kalinichev, M., Easterling, K. W., \& Holtzman, S. G. (2001). Early neonatal experience of Long-Evans rats results in long-lasting changes in morphine tolerance and dependence. Psychopharmacology, 157, 305-312. doi: $10.1007 / \mathrm{s} 002130100806$

Kaufman, J., Jones, B., Stieglitz, E., Vitulano, L., \& Mannarino, A. P. (1994) The use of multiple informants to assess children's maltreatment experiences. Journal of Family Violence, 9, 227-248. doi:10.1007/BF01531949

Kessler, R. C., McLaughlin, K. A., Green, J. G., Gruber, M. J., Sampson, N. A., Zaslavsky, A. M., .. . Williams, D. R. (2010). Childhood adversities and adult psychopathology in the WHO World Mental Health Surveys. British Journal of Psychiatry, 197, 378-385. doi:10.1192/bjp.bp.110. 080499

Knudsen, E. I. (2004). Sensitive periods in the development of the brain and behavior. Journal of Cognitive Neuroscience, 16, 1412-1425. doi:10. 1162/0898929042304796 
Kosson, D. S., Budhani, S., Nakic, M., Chen, G., Saad, Z. S., Vythilingam, M., . . Blair, R. J. R. (2006). The role of the amygdala and rostral anterior cingulate in encoding expected outcomes during learning. NeuroImage, 29, 1161-1172. doi:10.1016/j.neuroimage.2005.07.060

Lansford, J. E., Dodge, K. A., Pettit, G. S., Bates, J. E., Crozier, J., \& Kaplow, J. (2002). A 12-year prospective study of the long-term effects of early child physical maltreatment on psychological, behavioral, and academic problems in adolescence. Archives of Pediatrics and Adolescent Medicine, $156,824-830$

Leppänen, J. M., Milders, M., Bell, J. S., Terriere, E., \& Hietanen, J. K. (2004). Depression biases the recognition of emotionally neutral faces. Psychiatry Research, 128, 123-133. doi:10.1016/j.psychres.2004.05.020

Lim, L., Hart, H., Mehta, M. A., Simmons, A., Mirza, K., \& Rubia, K. (2015). Neural correlates of error processing in young people with a history of severe childhood abuse: An fMRI study. American Journal of Psychiatry, 172, 892-900. doi:10.1176/appi.ajp.2015.14081042

Martinez, D., Slifstein, M., Broft, A., Mawlawi, O., Chatterjee, R., Hwang, D., .. Laruelle, M. (2003). Imaging human mesolimbic dopamine transmission with positron emission tomography: Part II. Amphetamine-induced dopamine release in the functional subdivisions of the striatum. Journal of Cerebral Blood Flow and Metabolism, 23, 285-300. doi:10.1097/ 01.WCB.0000048520.34839.1A

Matthews, K., \& Robbins, T. W. (2003). Early experience as a determinant of adult behavioural responses to reward: The effects of repeated maternal separation in the rat. Neuroscience \& Biobehavioral Reviews, 27, 4555. doi:10.1016/S0149-7634(03)00008-3

Matthys, W., Vanderschuren, L. J., \& Schutter, D. J. (2012). The neurobiology of oppositional defiant disorder and conduct disorder: Altered functioning in three mental domains. Development and Psychopathology, 25, 1-15. doi:10.1017/S0954579412000272

May, A. C., Stewart, J. L., Migliorini, R., Tapert, S. F., \& Paulus, M. P. (2013). Methamphetamine dependent individuals show attenuated brain response to pleasant interoceptive stimuli. Drug and Alcohol Dependence, 131, 238-246. doi:10.1016/j.drugalcdep.2013.05.029

McCrory, E. J., De Brito, S. A., Kelly, P. A., Bird, G., Sebastian, C. L., Mechelli, A., . . Viding, E. (2013). Amygdala activation in maltreated children during pre-attentive emotional processing. British Journal of Psychiatry, 202, 269-276. doi:10.1192/bjp.bp.112.116624

McCrory, E. J., De Brito, S. A., Sebastian, C. L., Mechelli, A., Bird, G., Kelly, P. A., \& Viding, E. (2011). Heightened neural reactivity to threat in child victims of family violence. Current Biology, 21, 947-948. doi:10.1016/j.cub.2011.10.015

McCrory, E. J., Gerin, M. I., \& Viding, E. (2017). Annual Research Review: Childhood maltreatment, latent vulnerability and the shift to preventative psychiatry-The contribution of functional brain imaging. Journal of Child Psychology and Psychiatry, 58, 338-357. doi:10. $1111 /$ jcpp. 12713

McCrory, E. J., \& Viding, E. (2015). The theory of latent vulnerability: Reconceptualizing the link between childhood maltreatment and psychiatric disorder. Development and Psychopathology, 27, 493-505. doi:10.1017/ S0954579415000115

McLaughlin, K. A., Peverill, M., Gold, A. L., Alves, S., \& Sheridan, M. A. (2015). Child maltreatment and neural systems underlying emotion regulation. Journal of the American Academy of Child \& Adolescent Psychiatry, 54, 753-762. doi:10.1016/j.jaac.2015.06.010

Mehta, M. A., Gore-Langton, E., Golembo, N., Colvert, E., Williams, S. C. R., \& Sonuga-Barke, E. (2010). Hyporesponsive reward anticipation in the basal ganglia following severe institutional deprivation early in life. Journal of Cognitive Neuroscience, 22, 2316-2325. doi:10.1162/ jocn.2009.21394

Mueller, S. C., Maheu, F. S., Dozier, M., Peloso, E., Mandell, D., Leibenluft, E., . . . Ernst, M. (2010). Early-life stress is associated with impairment in cognitive control in adolescence: An fMRI study. Neuropsychologia, 48, 3037-3044. doi:10.1016/j.neuropsychologia.2010.06.013

Nagai, Y., Asada, M., \& Hosoda, K. (2006). Learning for joint attention helped by functional development. Advanced Robotics, 20, 1165-1181. doi:10.1163/156855306778522497

Nanni, V., Uher, R., \& Danese, A. (2012). Childhood maltreatment predicts unfavorable course of illness and treatment outcome in depression: A meta-analysis. American Journal of Psychiatry, 169, 141-151. doi:10. 1176/appi.ajp.2011.11020335

O'Doherty, J. P. (2011). Contributions of the ventromedial prefrontal cortex to goal-directed action selection. Annals of the New York Academy of Sciences, 1239, 118-129. doi:10.1111/j.1749-6632.2011.06290.x
O'Doherty, J. P., Dayan, P., Schultz, J., Deichmann, R., Friston, K., \& Dolan, R. J. (2004). Dissociable role of ventral and dorsal striatum in instrumental conditioning. Science, 304, 452-454. doi:10.1126/science.1094285

O'Doherty, J. P., Hampton, A., \& Kim, H. (2007). Model-based fMRI and its application to reward learning and decision making. Annals of the New York Academy of Sciences, 1104, 35-53. doi:10.1196/annals.1390. 022

Pani, L., Porcella, A., \& Gessa, G. L. (2000). The role of stress in the pathophysiology of the dopaminergic system. Molecular Psychiatry, 5, 14-21. doi:10.1038/sj.mp.4000589

Pollak, S. D., \& Tolley-Schell, S. A. (2003). Selective attention to facial emotion in physically abused children. Journal of Abnormal Psychology, 112, 323-338. doi:10.1037/0021-843X.112.3.323

Pollak, S. D., Vardi, S., Putzer Bechner, A. M., \& Curtin, J. J. (2005). Physically abused children's regulation of attention in response to hostility Child Development, 76, 968-977. doi:10.1111/j.1467-8624.2005. 00890.x

Pryce, C. R., Dettling, A. C., Spengler, M., Schnell, C. R., \& Feldon, J. (2004). Deprivation of parenting disrupts development of homeostatic and reward systems in marmoset monkey offspring. Biological Psychiatry, 56, 72-79. doi:10.1016/j.biopsych.2004.05.002

Puetz, V. B., Kohn, N., Dahmen, B., Zvyagintsev, M., Schüppen, A., Schultz, R. T., ... Konrad, K. (2014). Neural response to social rejection in children with early separation experiences. Journal of the American Academy of Child \& Adolescent Psychiatry, 53, 1328-1333. doi:10. 1016/j.jaac.2014.09.004

Puetz, V. B., Viding, E., Palmer, A., Kelly, P., Lickley, R., Koutoufa, I., . . Mccrory, E. (2016). Altered neural response to rejection-related words in children exposed to maltreatment. Journal of Child Psychology and Psychiatry. Advance online publication.

Radford, L., Corral, S., Bradley, C., \& Fisher, H. (2011). Child abuse and neglect in the UK today: Research into the prevalence of child maltreatment in the United Kingdom. London: National Society for the Prevention of Cruelty to Children.

Reeb-Sutherland, B. C., Levitt, P., \& Fox, N. A. (2012). The predictive nature of individual differences in early associative learning and emerging social behavior. PLOS ONE, 7, e30511. doi:10.1371/journal.pone.0030511

Rescorla, R. A., \& Wagner, A. R. (1972). A theory of Pavlovian conditioning: Variations in the effectiveness of reinforcement and nonreinforcement. Classical Conditioning: II. Current Research and Theory, 21, 64-99. doi:10.1101/gr.110528.110

Ridderinkhof, K. R., van den Wildenberg, W. P. M., Segalowitz, S. J., \& Carter, C. S. (2004). Neurocognitive mechanisms of cognitive control: The role of prefrontal cortex in action selection, response inhibition, performance monitoring, and reward-based learning. Brain and Cognition, 56, 129-140. doi:10.1016/j.bandc.2004.09.016

Rogosch, F. A., Dackis, M. N., \& Cicchetti, D. (2011). Child maltreatment and allostatic load: Consequences for physical and mental health in children from low-income families. Development and Psychopathology, 23, 1107-1124. doi:10.1017/S0954579411000587

Schoenbaum, G., Roesch, M. R., \& Stalnaker, T. A. (2006). Orbitofrontal cortex, decision-making and drug addiction. Trends in Neurosciences, 29, 116-124. doi:10.1016/j.tins.2005.12.006

Shackman, J. E., Shackman, A. J., \& Pollak, S. D. (2007). Physical abuse amplifies attention to threat and increases anxiety in children. Emotion, 7 838-852. doi:10.1037/1528-3542.7.4.838

Smoski, M. J., Felder, J., Bizzell, J., Green, S. R., Ernst, M., Lynch, T. R., \& Dichter, G. S. (2009). fMRI of alterations in reward selection, anticipation, and feedback in major depressive disorder. Journal of Affective Disorders, 118, 69-78. doi:10.1016/j.jad.2009.01.034

Smoski, M. J., Rittenberg, A., \& Dichter, G. S. (2011). Major depressive disorder is characterized by greater reward network activation to monetary than pleasant image rewards. Neuroimaging, 194, 263-270. doi:10. 1016/j.pscychresns.2011.06.012

Solomon, J., \& George, C. (1999). The place of disorganization in attachment theory: Linking classic observations with contemporary findings. In J. Solomon \& C. George (Eds.), Attachment disorganization (pp. 3-32). New York: Guilford Press.

Stringaris, A., Vidal-Ribas Belil, P., Artiges, E., Lemaitre, H., Gollier-Briant, F., Wolke, S., . . Paillère-Martinot, M.-L. (2015). The brain's response to reward anticipation and depression in adolescence: Dimensionality, specificity, and longitudinal predictions in a community-based sample. American Journal of Psychiatry, 172, 1215-1223. doi:10.1176/appi.ajp.2015. 14101298 
Tanaka, S. C., Doya, K., Okada, G., Ueda, K., Okamoto, Y., \& Yamawaki, S. (2016). Prediction of immediate and future rewards differentially recruits cortico-basal ganglia loops. In S. Ikeda, H. K. Kato, F. Ohtake, \& Y. Tsutsui (Eds.), Behavioral economics of preferences, choices, and happiness (pp. 593-616). Tokyo: Springer Japan.

Teicher, M. H., \& Samson, J. A. (2013). Childhood maltreatment and psychopathology: A case for ecophenotypic variants as clinically and neurobiologically distinct subtypes. American Journal of Psychiatry, 170, 1114-1133. doi:10.1176/appi.ajp.2013.12070957

Tottenham, N., Hare, T. A., Millner, A., Gilhooly, T., Zevin, J. D., \& Casey, B. J. (2011). Elevated amygdala response to faces following early deprivation. Developmental Science, 14, 190-204. doi:10.1111/j.1467-7687. 2010.00971.x

Ubl, B., Kuehner, C., Kirsch, P., Ruttorf, M., Diener, C., \& Flor, H. (2015). Altered neural reward and loss processing and prediction error signalling in depression. Social Cognitive and Affective Neuroscience, 10, 11021112. doi: $10.1093 / \mathrm{scan} / \mathrm{nsu} 158$

Valentin, V. V, \& O'Doherty, J. P. (2009). Overlapping prediction errors in dorsal striatum during instrumental learning with juice and money reward in the human brain. Journal of Neurophysiology, 102, 3384-3391. doi:10.1152/jn. 91195.2008

Ward, B. (2000). Simultaneous inference for fMRI data. AFNI 3rd Deconvolve documentation. Milwaukee, WI: Medical College of Wisconsin.

Wechsler, D. (1997). WAIS-III administration and scoring manual. San Antonio, TX: Psychological Corporation.

White, S., Fowler, K. A., Sinclair, S., Schechter, J. C., Majestic, C. M., Pine, D. S., \& Blair, R. J. (2014). Disrupted expected value signaling in youth with disruptive behavior disorders to environmental reinforcers. Journal of the American Academy of Child \& Adolescent Psychiatry, 5, 577-588. doi:10.1016/j.jaac.2013.12.023

White, S., Geraci, M., Lewis, E., Leshin, J., Teng, C., Averbeck, B., . . Blair, K. S. (2017). Prediction error representation in individuals with general- ized anxiety disorder during passive avoidance. American Journal of Psychiatry, 174, 110-117. doi:10.1176/appi.ajp.2016.15111410

White, S., Pope, K., Sinclair, S., Fowler, K. A., Brislin, S. J., Williams, W. C., ... Blair, R. J. R. (2013). Disrupted expected value and prediction error signaling in youths with disruptive behavior disorders during a passive avoidance task. American Journal of Psychiatry, 170, 315-323. doi:10.1176/appi.ajp.2012.12060840.disrupted

White, S., Tyler, P., Botkin, M. L., Erway, A. K., Thornton, L. C., Kolli, V., . . . Blair, R. J. (2016). Youth with substance abuse histories exhibit dysfunctional representation of expected value during a passive avoidance task. Neuroimaging, 257, 17-24. doi:10.1016/j.pscychresns.2016.08.010

White, S., Tyler, P. M., Erway, A. K., Botkin, M. L., Kolli, V., Meffert, H., . . . Blair, J. R. (2016). Dysfunctional representation of expected value is associated with reinforcement-based decision-making deficits in adolescents with conduct problems. Journal of Child Psychology and Psychiatry, 57, 938-946. doi:10.1111/jcpp.12557

Widom, C. S., Czaja, S. J., Bentley, T., \& Johnson, M. S. (2012). A prospective investigation of physical health outcomes in abused and neglected children: New findings from a 30-year follow-up. American Journal of Public Health, 102, 1135-1144. doi:10.2105/AJPH.2011.300636

Willner, P. (2005). Chronic mild stress (CMS) revisited: Consistency and behavioural-neurobiological concordance in the effects of CMS. Neuropsychobiology, 52, 90-110. doi:10.1159/000087097

Zénon, A., Duclos, Y., Carron, R., Witjas, T., Baunez, C., Régis, J., . . Eusebio, A. (2016). The human subthalamic nucleus encodes the subjective value of reward and the cost of effort during decision-making. Brain, 139, 1830-1843. doi:10.1093/brain/aww075

Zhang, W.-N., Chang, S.-H., Guo, L.-Y., Zhang, K.-L., \& Wang, J. (2013). The neural correlates of reward-related processing in major depressive disorder: A meta-analysis of functional magnetic resonance imaging studies. Journal of Affective Disorders, 151, 531-539. doi:10.1016/j.jad.2013. 06.039 